\title{
Analysis on Fast Breeder Reactor (FBR) Performances and Plutonium Production Profile of Loading Minor Actinide (MA) in FBR Blanket
}

\author{
Sidik Permana ${ }^{1^{*}}$, Mitsutoshi Suzuki ${ }^{2}$, Masaki Saito ${ }^{3}$ \\ ${ }^{1}$ Nuclear Physics and Bio Physics Research Group, Bandung Institute of Technology, \\ Gedung Fisika, Jl. Ganesha 10, Bandung 40132, Indonesia \\ ${ }^{2}$ Department of Science and Technology for Nuclear Material Management (STNM), \\ Japan Atomic Energy Agency (JAEA), \\ 2-4 Shirane, Shirakata, Tokai Mura, Naka-gun, Ibaraki 319-1195 Japan, \\ ${ }^{3}$ Research Laboratory for Nuclear Reactors, Tokyo Institute of Technology \\ 2-12-1 O-Okayama, Meguro-ku, Tokyo 152-8550, Japan
}

Received: 15 January 15, 2012, Revised: 5 May 2012, Accepted: 2 June 2012

\begin{abstract}
An investigated process of recycling option based on minor actinide (MA) composition in the reactor design has been investigated which is based on fast breeder reactor (FBR) type as reference reactor type. The paper investigated some significant parameters of reactor operation, fuel sustainability and nuclear non-proliferation point of view. As initial fuel composition some composition of light water reactor (LWR) spent fuels are used and loaded into the such as mixed oxide (MOX) in the core regions and minor actinide doping is loaded into blanket regions. It is shows that criticality condition as indicating reactor operation time is obtained less for loading MA case in the blanket regions in comparing with no loading MA. It indicates a shorter reactor operation time is obtained for loading MA than without loading MA. Conversion rasio level or breeding rasio, is obtained less conversion rasio for loading MA which shows less fissile material production when some portion of U-238 is replaced by MA loading. Although, during reactor operation, some fissile plutonium materials such as $\mathrm{Pu}-239$ are also produced from MA loading, however, it still less production in comparing with fissile plutonium production from direct process from converted U-238. It shows more Pu-238 can be produced than $\mathrm{Pu}-240$ because of main portion of MA is $\mathrm{Np}-237$ which can be directly produce more $\mathrm{Pu}-238$ than $\mathrm{Pu}-$ 240. As protected plutonium composition ( $\mathrm{Pu}-238$ and $\mathrm{Pu}-240)$, loading $\mathrm{MA}$ produces some even mass plutonium isotopes in the blanket regions and loading $5 \%$ of MA doping, obtains more than enough composition based on Kessler'criterion to estimate the level of technical difficulty for contructing explosive nuclear devices based on internal heating of $\mathrm{Pu}-238$.
\end{abstract}

Keywords: Recycling fuel, minor actinide, LWR spent fuel, FBR, criticality, conversion ratio, nuclear non-proliferation

\section{INTRODUCTION}

How to manage and utilize nuclear spent fuel especially from the reactors operation have been progressively discussed and developed some idea and model in term of theorytical, analytical based, as well as experimental based, and further more how to use it in large scale deployment such as for commercial reactor based. These topic become more interesting to be analyzed becuase some benefit and

* Corresponding author.

E-mail address: psidik@fi.itb.ac.id advantages such as capable reduce the environment impact caused by reduction of nuclear waste, longer fuel utilization as fuel sustainability and economic aspects because of more fuels can be used and reactor operation can be operated longer as well as from view point of nuclear non-proliferation aspect because of high technical barrier for utilize spent fuel and protected plutonium production can be obtained [1-5]. Some large quantity of accumulated spent fuels (SF) from discharged fuel of light water reactor (LWR) can be managed and fully optimized it fuel utilization by adopting recycling option than once through fuel option such as reprocessed 
recycling uranium and plutonium from spent fuel LWR as new fresh fuels. In addition, the option to recycle minor actinide (MA) also should be considered for reducing its actinides accumulation as well as the advantege to produce more protected plutonium composition. Closed cycle option or recycling fuel process for both reactor types such as thermal neutron reactor type and fast reactor type including some other innovative reactor types for generation 4 reactors can be applied and optimized. Some advantages have been shown by fast neutron reactor technology, such as high fuel breeding and high level of reducing spent fuels because of fast breeder reactor (FBR) type obtains criticality condition easier and higher fuel breeding caused by the characteristics of high eta value of fissile materials at fast neutron energy region. Furthermore, loading MA in the reactors gives some benefites to improve higher level of nuclear nonproliferation from converted MA into plutonium actinides through absorption process of excess neutrons [6-10].

Recycling program of transuranic (TRU) such as MOX fuel composition and MA fuel composition is adopted and shows some advantages to be loaded into fast reactor technology either it can be loaded into core reactor region as well as blanket regions. Several options for recycling transuranic have already been conducted in progressive way for a purpose of extending reactor operation time for longer operation program $[9,10]$. Loading LWR spent fuel also showed a significant results for high burning MA capability purposes [11], and in some cases to improve transmutation of transuranic (TRU) [12,13]. Reduction level of proliferation potential of nuclear material utilization for nuclear non-proliferation issue to be carried out not only for political level point of view, but also optimum fuel utilization only for civil purposes. Characteristics of material barrier based on isotopic material barrier is one of the option to estimate the level of proliferation resistance based on intrinsic nuclear non-proliferation aspect. The level of material barrier from the isotopic material is caused by high intensity level of decay heat (DH) and level of spontaneous fission neutron (SFN). High level of material barrier is shown by increasing of even mass number composition of plutonium isotopes. Transmutation option can be adopted loading minor actinide (MA) in the reactors to produce more protected plutonium proliferation by high composition of even mass of plutonium from converted Material [1-5]. In this paper, it will show and discuss some evaluated issues regarding reactor performance of FBR design in term of reactor oepration, nuclear fuel sustainability aspect from fuel breeding point of view, and in relation to intrinsic proliferation resistance aspects of protected plutonium production.

\section{ANALYSIS METHOD}

As basic parameter of investigated analysis, some fuel composition of LWR type was obtained by using ORIGEN code [14] for fuel behavior and fuel composition analysis for different burnup and decay fuel time based on PWR type. Fuel behaviors of LWR from initial fresh fuel up to end operation as well as cooling process after discharged fuel from the reactors are adopted based on some key parameters of fuel burnup level such as $50 \mathrm{GWd} / \mathrm{t}$ and decay times' processes of 30 years cooling time. Actinide compositions are sensitive to burnup level and decay time in particular for some plutonium isotopes and minor actinides [15]. As a focus analyses in this present study, TRU compositions of LWR SF are used as initial fresh fuel to be loaded in the FBR of core-blanket arrangement system.

As a basic reactor design, FBR system was reffred as a core-blanket fuel arrangement based which is adjusted core regions for maintaining criticality and blanket regions for fuel breeding regions which reffered to a large FBR design of $\mathrm{FaCT}$ program as reference case for whole core reactor optimization [16]. A combined integrated code system was used for evaluating reactor core behavior based on space dependency, and time dependency in relation to burnup dependency for whole FBR core configuration and for nuclide data library, it was used JFS-3-J-3.2R which is based on the JENDL 3.2 [17-20].

Reactor performances of FBR design are also included fuel breeding analysis and criticality performance of the reactor. Fuel breeding capability is referred to a breeding ratio level of FBR, which is based on the ratio of reaction rate of fertile materials and fissile materials. Actinide compositions as main material for breeding ratio analysis, some fertile materials are adopted such as U-238 and Pu-240, including $\mathrm{Pu}-238$. Fertile materials are used for this analysis such as U-235, $\mathrm{Pu}-239$ and $\mathrm{Pu}-241$. $\mathrm{Pu}-238$ is used for fuel breeding analysis based on the consideration that $\mathrm{Pu}-238$ can be used as fertile material which will convert to $\mathrm{Pu}-239$ from capturing neutron and $\mathrm{Pu}-238$ production will be more significant by adopting MA doping option into the system.

Analysis on isotopic plutonium composition analysis is conducted based on on vector composition of each plutonium isotope in the 
blanket regions of FBR. To analyze protected plutonium production level, some categorizations of plutonium which is based on plutonium vector compositions have been adopted for several plutonium grades or categorizations [1-5]. Those composition of isotopic plutonium has specific parameters for material barriers of plutonium such as effect of decay heat (DH) activity and spontaneous fission neutron (SFN). Material barrier has sensitive to typical isotopic plutonium vectors such even mass plutonium of $\mathrm{Pu}-238, \mathrm{Pu}-240$ and $\mathrm{Pu}-242$ which is adopted to estimate the level of material barrier in regard to the level of technical difficulties to construct a nuclear explosive device from internal heating of $\mathrm{Pu}-238$ decay heat and more difficult to control pre-initiation of high explosive from spontaneous fission neutron [3-5].

\section{RESULTS AND DISCUSSION}

Some result of reactor operation, fuel sustainability and nuclear non-proliferation aspect will be shon in this section based on large FBR type. Some obtained investigation results of MOX fuel in the core and MA loading in the blanket regions will be shown and discussed in this section which consists of some analyses of fuel breeding, reactor criticality condition and protected plutonium production which is shown by isotopic plutonium composition aspect. Transuranic material gives some effect to the reactor performance as well as inventory balance of plutonium and MA as well as isotopic plutonium production during reactor operation. Whole reactor core analysis was done for criticality and fuel breeding analysis of the reactor. In case of plutonium isotopes analyses, different fuel regions have been adopted such as plutonium composition in the core regions and in the blanket regions.

\section{Criticality Condition and Effect of Loading MA}

Obtained results of criticality condition for no loading MA and loading MA cases in the blanket FBR regios are shown in Figure 1 at the beginning of cycle or the initial stage of reactor operation. Loading MA in the blanket regions of FBR type cases the reduction value of criticality condition which causes a reduction time of reactor operation. As shown in Fig. 1, loading MA of $5 \%$ in the blanket regions gives reduction criticality performance of about less than $0.2 \%$ reduction value. Loading MA affects to less nuclear fission process caused by high capturing produced neutron by MA material as absorption material to be converted to other actinides. Less fission process and more capturing process are effective to reduce the criticality condition by any material which works as fertile material, absorben as well as burnable poisson material. In this case, MA plays as fertile material which captures more neutron for conversion process in blanket FBR regions to be used for converting MA into other actinides such as plutonium

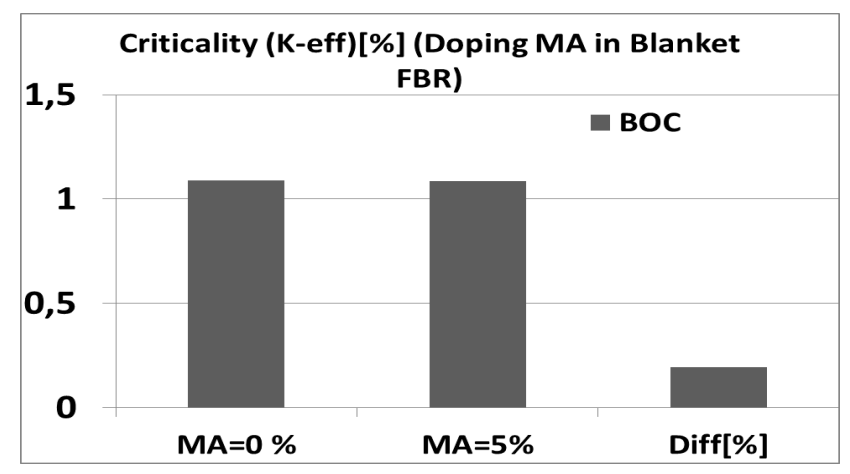

Figure 1 Criticality performances of loading fuel MA type in the blanket region of FBR at beginning of cycle (BOC)

\section{Fuel Conversion Capabilities and Loading MA Effect}

As mentioned in the previous section, loading MA in the blanket regions of FBR shows a reduction crictiality condion because of the existance of MA in the blanket works as fertile material which will be effective to produce more converted new fuel such as plutonium through conversion process of capturing neutron. Obtained results for comparison analysis of conversion rasio of no loading MA and loading MA cases at the equilirbium condition are shown in Figure 2.

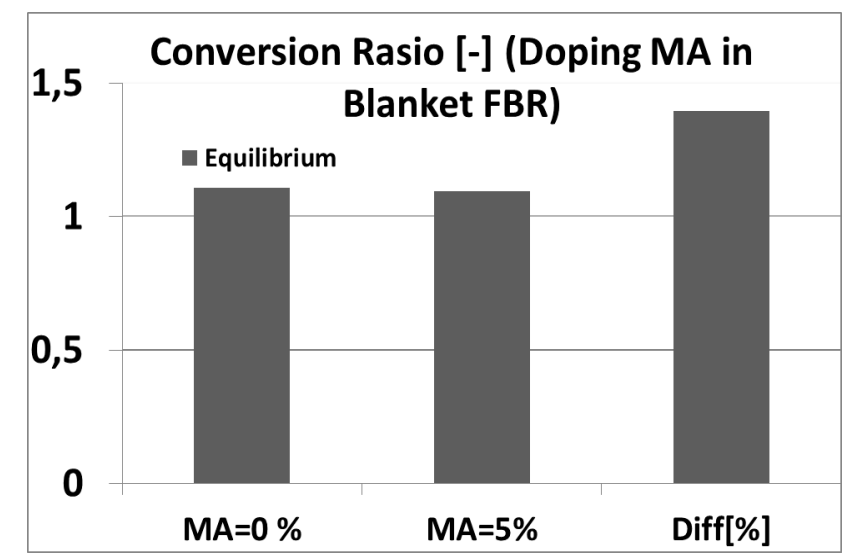

Figure 2 Conversion Rasio of Loading MA in the Blanket Regions FBR at end of equilibrium cycle (EOEC)

The results shows, loading MA of 5\% case obtains less conversion rasio value comparing with no loading MA case which shows about less than 
$1.5 \%$ a reduction value of conversion rasio. Loading $5 \%$ MA material in the blanket regions causes a reduction composition of natural uranium in the blanket regions of about $5 \%$ less. Natural uranium which consist of U-238 as a major material is a potential material to be used for converted material to produce more $\mathrm{Pu}-239$ as fissile material. MA material aslo can be used to produce more plutonium quantity such as $\mathrm{Pu}-238$ and converts to $\mathrm{Pu}-239$ which also shows MA as fertile material similar to U-238. Based on the results, conversion process of MA is still less comparing with the conversion quantity of $\mathrm{U}-238$ to produce more fissile plutonium materials. This fissile plutonium production is used as indicator for conversion rasio process and if the conversion rasio level is more than unity, it can be called as breeding rasio which means how large fissile materials are produce as additional excess fissile which can be used for further fuel utilization.

\section{Composition of Plutonium Isotope in Blanket FBR Regions}

Converted material phenomena from capturing neutron process will produce some typical new materials which is based on the initial converted materials. In case of pure natural uranium loading into the balnket regions of FBR reactors will produce much more fissile plutonium isotope of $\mathrm{Pu}$ 239 as major material. Isotope $\mathrm{Pu}-239$ as a potensial fissile material is produced from conversion process of U-238 through neutron capture process. Meanwhile, MA conversion process produces some plutonium isotopes, however the main actinide is $\mathrm{Pu}-238$ and some additional $\mathrm{Pu}-240$ and some small amunt of $\mathrm{Pu}-242$, which can be recognized as even mass plutonium production material. In the reactor, some $\mathrm{Pu}-238$ also can be converted into $\mathrm{Pu}-239$ after capturing neutron process, therefore, in limited quantity, produced even mass plutonium from MA also will produce $\mathrm{Pu}-239$ as a main contributor for conversion rasio quantity.

As mentioned in the previous section, for nuclear non-proliferation view point, MA gives some advantages such as converted MA will produces protected plutonium composition. This protected pltuonium is composed by even mass plutonium isotopes such as $\mathrm{Pu}-238, \mathrm{Pu}-240$ and $\mathrm{Pu}-$ 242. As representative plutonium isotopes, it has been chosen $\mathrm{Pu}-238$ and $\mathrm{Pu}-240$ isptopes for analysis and comparative studies because of some major quantity of even mass plutonium fraction in total plutonium vector composition. Obtained isotopic plutonium compositions of $\mathrm{Pu}-238$ and $\mathrm{Pu}-$ 240 in the blanket regions are shown in Figures 3 and 4.

Figure 3 shows production of isotopic vector composition of $\mathrm{Pu}-238$ and $\mathrm{Pu}-240$ during reactor operation (days) from beginning of operation up to some irradiation time of reactor operation. It shows

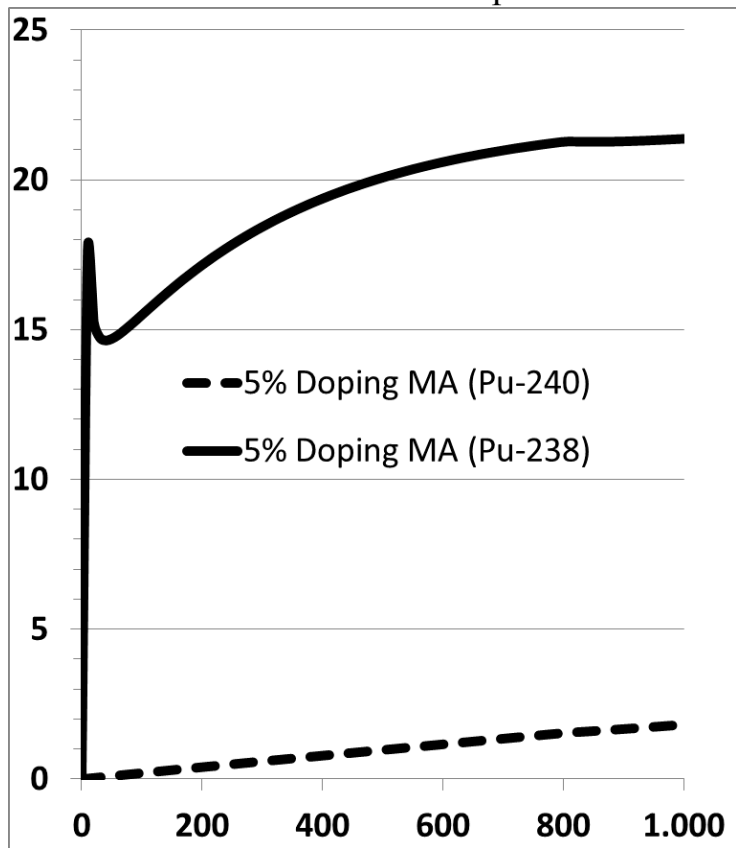

Figure 3 Isotopic Plutonium Vector Composition of $\mathrm{Pu}-$ 238 and $\mathrm{Pu}-240$ in the Blanket Regions FBR for 5\%

Loading MA loading fuel type in the core region of FBR

the production of both $\mathrm{Pu}-238$ and $\mathrm{Pu}-240$ isotopes increase with increasing reactor operation time. In addition, $\mathrm{Pu}-238$ production gives a significant production rate from the beginning of irradiation time especially for early irradiation time process and it increases slowly by increasing the time up to some extended operation time the composition will reach a constant value. Loading MA rate of $5 \%$ gives more than $15 \% \mathrm{Pu}-238$ composition from the beginning of operation and some addition production rate from $\mathrm{Pu}-240$ for less than $5 \%$ composition. From production point of view, $\mathrm{Pu}-$ 238 plays as a major contributor for protected plutonium quantity level which can be used as a parameter for increasing material barrier of intrinsic nuclear non-proliferation aspect. 


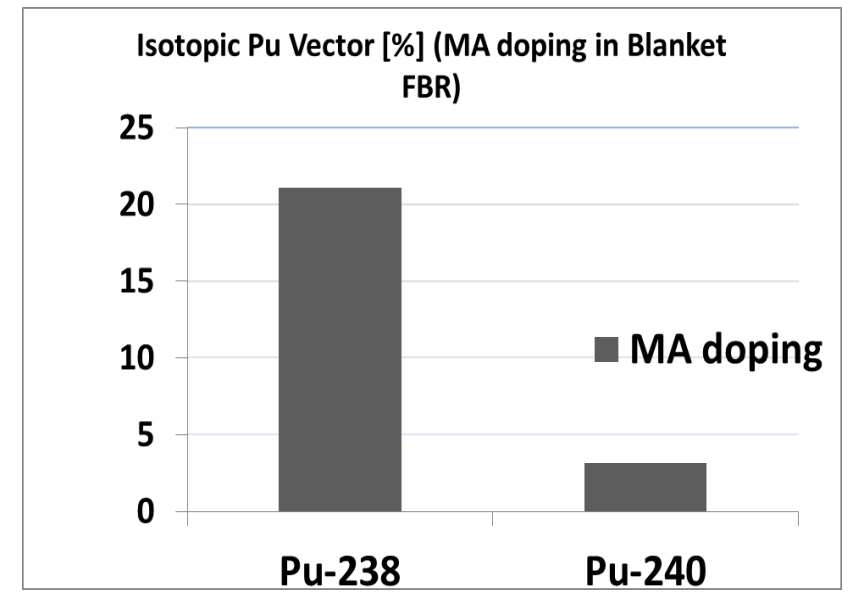

Figure 4 Equilibrum composision of $\mathrm{Pu}-238$ and $\mathrm{Pu}-240$ in the Blanket Regions FBR

Comparison results of isotopic vector composition of $\mathrm{Pu}-238$ and $\mathrm{Pu}-240$ at equilibrium condition for loading MA case in the blanket regions is shown in Fig. 4. At equilibrium condition, major actinides reach a constant level including production of plutonium isotopes. In equilibrium condition, isotopic $\mathrm{Pu}-238$ composition produce more than $20 \%$ vector composition as well as $\mathrm{Pu}$ 240 of about $3 \%$ composition. Blanket regions have softer neutron spectra in comparing with core regions of the reactors which effectively produces more $\mathrm{Pu}-238$ from converted MA. Therefore, capturing process is much higher than fission process in the balnket regions therefore, breeding material process in more effective. Because of directly main production of converted $\mathrm{MA}$ is $\mathrm{Pu}-238$ becuase of the majority material of MA is Np-237 which effective converted to $\mathrm{Pu}-238$, therefore $\mathrm{Pu}$ 238 obtains much higher than $\mathrm{Pu}-240$. Pu-240 can be produced from additional neutron capture from $\mathrm{Pu}-238$ into $\mathrm{Pu}-239$ and into $\mathrm{Pu}-240$, and other way from some minor actinide such as curium.

To evaluate the sufficient level of intrinsic proliferation resistance, as basic parameter, protected plutonium production level will be evaluated based on some categorizations of plutonium for several plutonium grades or categorizations [1-5] which referes to even mass plutonium composition of $\mathrm{Pu}-238, \mathrm{Pu}-240$ and $\mathrm{Pu}-$ 242. This parameter as a basic parameter to estimate the technical difficulty level of constructing explosive nuclear in regard to their barrier of heat control parameter for a nuclear explosive device from decay heat level and control mechanism for control pre-initiation of high explosive from spontaneous fission neutron level. In case of blanket regions, becasue of high production of $\mathrm{Pu}-238$ and less production of $\mathrm{Pu}-240$, it can be chosen as a representative of single parameter of even mass plutonium. Pu-238 can be used as representative, although it can be added by small portion of $\mathrm{Pu}-240$ in other way. Focused on $\mathrm{Pu}-238$ vector composition, more than $20 \%$ composition of $\mathrm{Pu}-238$ is much more than enough to fulfill a minimum requirement for protected plutonium production based on Kessler's proposal. Kessler mentioned that $9 \%$ of $\mathrm{Pu}-238$ composition is enough to protec plutonium production to be used for explosive materials. This estimation is based on the internal heating process of Pu-238 which has very high decay heat level which can directly destroy a sorrounding material caused by high heat level.

\section{CONCLUSION}

Some analysis of recycling option of MA in the reactor design has been investigated for several comparative reactor performances and material production of plutonium during reactor operation. The study investigated some significant parameter of reactor operation based on criticality condition, fuel sustainability based on breeding performance of the reactor, and nuclear non-proliferation point of view based on protected plutonium production of $\mathrm{Pu}-238$. Some composition of LWR spent fuels are used as initial fuel and it is loaded into the FBR system for several typical loaded fuels such as mixed oxide (MOX) in the core, and minor actinide doping to be loaded into blanket regions. Criticality condition is less for loading MA in the blanket regions comparing with no loading MA which indicates a shorter reactor operation time is obtained for loading MA. In case of conversion rasio or breeding rasio process, less conversion rasio is obtained by loading MA which shows less fissile material production when some portion of U-238 is replaced by MA loading, although some fissile plutonium materials are also produced from MA loading, however, it still less production in comparing with fissile plutonium production from direct conveter from U-238. Loading MA produces some even mass plutonium isotopes in the blanket regions as protected plutonium composition $(\mathrm{Pu}-238$ and $\mathrm{Pu}-240$ ), which shows more $\mathrm{Pu}-238$ can be produced than $\mathrm{Pu}-240$ because of main portion of MA is Np-237 which can be directly produce more $\mathrm{Pu}-238$ than $\mathrm{Pu}-240$. Based on the production of $\mathrm{Pu}-$ 238 from loading $5 \%$ of MA doping, it is more than enough to protect plutonium production based on Kessler'criterion as a parameter for level of difficulty for contructing explosive nuclear devices based on internal heating of Pu-238. 


\section{REFERENCES}

[1] M. Saito, "Multi-Component Self-Consistent Nuclear Energy System for Sustainable Growth", Prog. in Nucl. Energy, 40[3-4], 365 (2002).

[2] International Atomic Energy Agency, Information Circular, INFCIRC/153, (1972).

[3] B. Pellaud, "Proliferation aspects of plutonium recycling," J. Nucl. Mater. Managements, XXXI, No. 1 (2002).

[4] G. Kessler, "Plutonium denaturing by $\mathrm{Pu}$ 238," The First Int. Sci. Technol. Forum on Protected Plutonium Utilization for Peace and Sustainable Prosperity, March 1-3, 2004, Tokyo, Japan.

[5] G. Kessler, "Plutonium denaturing by $\mathrm{Pu}$ 238," Nucl. Eng. Des., 155, 53-73 (2007).

[6] Y. Meiliza, M. Saito and H. Sagara., "Protected Plutonium Breeding by Transmutation of Minor Actinides in Fast Breeder Reactor", J. Nucl. Sci. Technol.,, Vol. 45[3], 230 (2008).

[7] S. Permana, M. Suzuki, M. Saito, "Effect of TRU Fuel Loading on Core Performance and Plutonium Production of FBR", Nucl. Eng. Des, 241, 101-117 (2011).

[8] S. Permana, M. Suzuki, M. Saito, "Basic Analysis on Isotopic Barrier of Material Attractiveness Based on Plutonium Composition of FBR", J. Nucl. Sci. Technol., 48[5], 724-733 (2011).

[9] S. Permana., Z. Suud, "Core Performance and Plutonium Production of Small Long Life Fast Reactor using Doping Actinides", Proc. of ICAPP, May 10-14, 2009, Tokyo-Japan.

[10] S. Permana., Z. Suud, and M. Suzuki, 2009, "Trans-uranium doping utilization for increasing protected plutonium proliferation of small long life reactor", Proc. of Global, September 6-11, 2009, Paris, France.
[11] H. Choi and T. J. Downar, "A Liquid-Metal Reactor for Burning Minor Actinides of Spent Light Water Reactor Fuel-I: Neutronics Design Study" , Nucl. Eng. Des., 133, 1-22 (1999).

[12] Edward A. Hoffman and Weston M. Stacey, "Comparative Fuel Cycle Analysis of Critical and Subcritical Fast Reactor Transmutation Systems", Nucl. Technol., 144, 83 (2003).

[13] T. A. Taiwo, et al., "Assessment of a Heterogeneous PWR Assembly for Plutonium and Minor Actinide Recycle", Nucl. Technol., 155, 34 (2006).

[14] S. B. Ludwig and A. G. Croff., "ORIGEN 2.2 Isotope Generation and Depletion Code Matrix Exponential Method", Oak Ridge National Laboratory (2002).

[15] S. Permana, M. Suzuki, M. Saito, Proliferation Resistance Analysis of Plutonium from LWR during multi-recycling with MA in FBR, Proc. of ICAPP, May 16-19, 2011, Chiba-Japan.

[16] S. Ohki, et al., "Design Study of Minor Actinide Bearing Oxide Fuel Core for Homogeneous TRU Recycling Fast Reactor System", The 10th OECD/NEA P\&T Meeting, October 6-10, 2008, Mito, Japan.

[17] M. Nakagawa, K. Tsuchihashi, "SLAROM: A Code for Cell Homogenizations Calculation of Fast Reactor", JAERI 1294, Japan Atomic Energy Research Institute (1984).

[18] T. B. Fowler, D. R. Vondy, G. W. Cunningham, "Nuclear Reactor Core Analysis Code: CITATION", Oak Ridge National Laboratory report, ORNL-TM-2496, Rev2, USA (1971)

[19] G. Chiba et al., "The Revision of Nuclear Constant Set for Fast Reactor JFS-3-J3.2," J. At. Energy Soc. Jpn., 14, 335 (2002).

[20] T. Nakagawa et al., "Japanese Evaluated Nuclear Data Library Version 3 Revision-2: JENDL-3.22, J. Nucl. Sci. Technol., 32, 1259 (1995). 